Investigations

\title{
Theoretical Construction of Job Satisfaction in Medical Professionals Working for Mexican Companies
}

\author{
${ }^{1,2}$ María del Carmen López-García and ${ }^{2}$ María de los Ángeles Aguilera-Velasco \\ ${ }^{I}$ Escuela Nacional de Medicina y Homeopatía, Instituto Politécnico Nacional, D.F., México \\ ${ }^{2}$ Centro Universitario de Ciencias de la Salud, Universidad de Guadalajara, Jalisco, México
}

Article history

Received: 13-08-2015

Revised: $21-10-2015$

Accepted: 21-10-2015

Corresponding Author:

María del Carmen López-García

Escuela Nacional de Medicina y

Homeopatía, Instituto Politécnico

Nacional, D.F., México

Tel: 525551191620

Email: mc.lopzg@gmail.com

\begin{abstract}
Occupational Health physicians coexist in a work environment where they perform activities other than the ones developed by other doctors. Hence, there is interest in analyzing the theoretical construction of their job satisfaction. Inductive and qualitative study was conducted based on grounded theory and with the support of the software Atlas-ti. As a result of carrying out in-depth interviews and through the open, axial and selective coding process, 12 categories and five dimensions were integrated. They shaped the final definition of job satisfaction of these professionals. The conclusions showed that they are currently satisfied, although they were not satisfied at the beginning of their work life.
\end{abstract}

Keywords: Theoretical Construction, Occupational Health Physicians, Grounded Theory, Job Satisfaction

\section{Introduction}

The International Labor Organization (ILO) and the World Health Organization (WHO) established in 1950 and updated in 1995, that the purpose of the work of professionals engaged in occupational health in enterprises is to adapt work to man and each man to his activity (ILO, 1998; 1985).

ILO specifies in its Convention 161, Chapter II that the work of these professionals should, among others, aim to: Uncover the factors in work environments and work-practices that may affect the health of workers; participation in the development of programs to improve work practices and to monitore the workrelated health of employees.

This means that the job of these doctors requires a wide range of knowledge and skills, many of which were not learned during their medical training therefore they should receive specialized training. Moreover, although they are part of the medical profession, they differ because they do not work in a hospital along with. That is why it is considered a unique and complex group and therefore, the interest to explore and analyze the theoretical construction that they drew on their job satisfaction.

In terms of job satisfaction, it is defined as a worker's attitude towards their job in terms of the perception of it (Cuadra and Veloso, 2007).
GALLUP (2013) reports that in Mexico only 12\% of workers are fully satisfied and engaged to their jobs; and that $28 \%$ of them definitely dislike their work.

Job satisfaction, referenced in a review of surveys for quality of work life (2006-2010), performed annually in Spain, Rico (2012), found that it was higher in women and it was increased by: Job stability; employee's involvement in the company, a good business climate and the balance between work and family life.

Qualitative studies on job satisfaction that consider the "emic" posture, that is the point of view of the actors, also show indicators, but they have different kind of proposals. For example, the study on a French company dedicated to wine and liquors, found that workers at the lower hierarchical level are the ones who perceived the most dissatisfaction because of inadequate salaries; the middle level workers searched mainly their professional development and the intention of a promotion to a higher executive level; and the highest level functionaries considered the non financial satisfactors and their status more important (Galanou et al., 2011).

Another qualitative research applied to health personnel in nursing (Cousins and O'Donnell, 2011), concluded that having a greater professional responsibility, such as the power to prescribe drugs, increases the level of stress but also increases the job satisfaction, for being able to work with autonomy and 
independence. Both, nurses from Alberta, Canada as well as the Spanish building workers, consider their job "fun" (Reutter and Ford, 1996), because they have wide a variety of tasks and they feel valued, although the latter recognized that their work load is heavy and sometimes highly dangerous (Navarro-Astor et al., 2012).

In this study, we applied Grounded Theory that is meant to build theory rather than test theory. This way, we sought to analyze during 2014, the theoretical construction of job satisfaction of physicians dedicated to Occupational Health in Mexican companies.

\section{Materials and Methods}

To reference what Patton (2001) says about Grounded Theory, the theory emerges from the systematic comparative analysis and is based on the fieldwork to explain what has been observed.

Strauss and Corbin (2002) show the steps and procedures by connecting induction and deduction procedures, with the theoretical sampling, the coding procedure and the constant comparative method. Finally, the concepts are the building blocks of the theory.

The theory is systematically worked out according to the data that is obtained during the course of the research. The objectivity enables the researcher to have confidence that the results are a reasonable and impartial representation of a problem under investigation, whereas sensitivity enables creativity and the discovery of new theory from the data obtained (Strauss and Corbin, 2002).

The selection criteria for the physicians who participated on this research were that they had to be doctors who have been working for Mexican companies at least for two years.

The study was conducted on ten doctors, of which five were male and five female, $60 \%$ were married, $30 \%$ were single and $10 \%$ of them partnered. Their ages ranged from 26-59 years with average of $37.50(+/-$ 11.81) years. Occupational Health seniority was 2-33 years, mean 10.7 years (Table 1).

In-depth interviews with opened questions were applied to these doctors. Some of the questions asked were: How is a normal workday for you? Or: Why did you decide to work in Occupational Health? Or: What kind of satisfaction does this labor provide to you?

\section{Results}

The interviews were processed with the Atlas-ti software. A total of 243 quotations were obtained, with which 203 codes were formed. They were integrated into twelve categories and grouped into five dimensions that shaped the final category of job satisfaction, shown in the following Fig. 1.

From the 12 integrated categories referred above, we can establish the following:

\section{Category 1: My Motives of Choice}

Participating doctors who work in Occupational Health reported that they had chosen this area because various reasons, such as: "they found an opportunity", "they fell to bounce" or "by random of destiny".

\section{Category 2: I Changed my life}

Physicians said that during the time they had worked in the Occupational Health area, they changed their "life goals", "their attitude", "they learned how to delegate and to organize" and also to "enjoy living and working together with their colleagues who are not doctors".

\section{Category 3: Opportunities and Projects}

Regarding the opportunities that participants glimpsed for their development and growth in their job area and their future projects, only some noticed this opportunity in the company they work in. Moreover they highlighted they had academic projects, such as posting or planning Masters type or $\mathrm{PhD}$ and they had also administrative projects, such as working as coordinators or working for transnational companies.

\section{Category 4: Balance Between Personal life and Work}

The opinion about the existence of the balance between their personal life and work, described by the participants, was not unanimous. In general physicians that were interviewed did not refer to the family as the main or only instance they want to reconcile with their work, as indicated by ILO. Some of them commented that they wanted to continue studying (courses, masters or doctorate) during their spare time.

Table 1. Sociodemographic data of physicians working in occupational health for Mexican companies, 2014

\begin{tabular}{lllllrl}
\hline Physician & Sex & Age (Years) & Marital status & School & Antiquity (Years) & Turn \\
\hline 1 & M & 26 & Single & Postgraduate Studies & 2 & Night \\
2 & F & 34 & Married & Doctor & 8 & M-E \\
3 & F & 31 & Married & Post graduated & 4 & M-E \\
4 & M & 26 & Single & Doctor & 2 & M-E \\
5 & M & 59 & Married & Doctor & 33 & M-E \\
6 & F & 30 & Partnered & Doctor & 19 & M-E \\
7 & F & 53 & Married & Doctor & 29 & M-E \\
8 & M & 54 & Married & Postgraduate studies & 3 & M-E \\
9 & M & 28 & Married & Post graduated & 6 & M-E \\
10 & F & 33 & Single & Post graduated & M-E \\
\hline
\end{tabular}




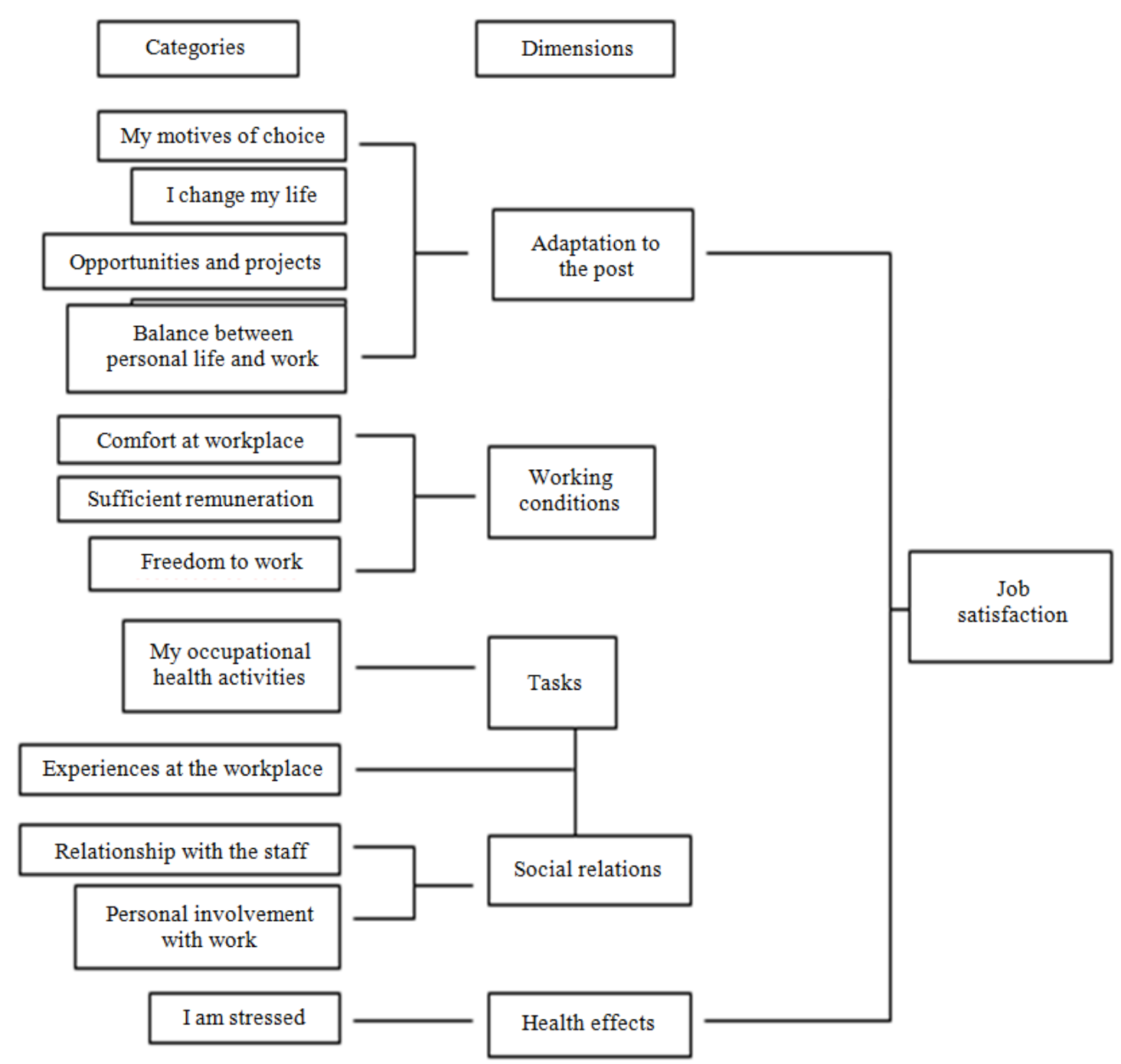

Fig. 1. Categories and dimensions

They expressed that available "free time" is restricted due to "high demand of work" that is established by the company.

Finally, they pointed out that a balance in their lives is not desired and they "are masochists" because once they achieve the balance, they "will seek new activities in order to feel uncomfortable".

\section{Category 5: Comfort at Workplace}

Participants considered living near their workplace, having a comfortable schedule and stability in their job as very important. Some of them mentioned that this stability was based on the effectiveness of their labor, in order to achieve their goals.

\section{Category 6: Sufficient Remuneration}

Some of the participants argued that the payment they receive for their work is good but "not enough to cover their needs in the future". However they consider it fair and think "they are not being exploited".

\section{Category 7: Freedom to Work}

The freedom at work generates job satisfaction among participants. However, some of them commented that they didn't have any supervision and others said it was very strict (they are being "controlled" all the time).

\section{Category 8: My Occupational Health Activities}

Participants said that the activities performed by them were essentially preventive in nature (medical entrance exams and periodical examinations, training, work risk detection) as well as care activities and administrative. This kind of preventive work they carried out, by itself, was very satisfactory. 


\section{Category 9: Experiences at the Workplace}

With regards to negative experiences at work, physicians expressed that the worst that they experienced were the seriously injured employees or with fatal outcome, that they had to attend. They also commented that they were unsatisfied because they didn't receive any support for the work that they had done, as well as a lack of resources for doing their work, lack of respect or lack of recognition to the work they performed.

As for positive experiences, the doctors referred the gratitude expressed by employees for their work as a very important experience. Likewise, the physicians assured they were very particularly satisfied because of the recognition by their chiefs' and the entire company in general. One of the best experiences they recall is "seeing the health employees benefitting" as well as "being able to reduce payments to IMSS or fines that the company has to cover".

Some of them showed their enthusiasm for being able to diagnose and/or to attend difficult health problems (accidents and diseases) or for finishing a project.

\section{Category 10: Relationship with the Staff}

Participants commented their job satisfaction with the relationship with their peers, that was good; and their relationship with the employees, that was cordial. However, some of them mentioned that their relationship with their mangers was weak.

\section{Category 11: Personal Involvement with Work}

The participants mentioned that feeling part of the company is a very important work satisfactory reason. Participants spoke enthusiastic, referring to the factory where they work as "my company".

Similarly but more generally, they said that they themselves and their knowledge are the result of what they live and do at their job.

\section{Category 12: I am Stressed}

Among the participants, there was a consensus on the fact that stress is the main effect on their health because of the work they do, but they like this stress because they consider it as part of their work and as they said, it is transitional.

Dimensions as adaptation to the post, working conditions, tasks, social relations and health effects, were integrated into the twelve categories, mentioned above. Finally, according to all these dimensions, the theoretical construction of job satisfaction in medical professionals was shaped.

According to the point of view of the physicians who work on occupational health, the definition of job satisfaction is: The sensation of well-being while working, which results with the process of adapting doctors to their company, is determined by their activities, the presence of working conditions and social relations in their workplace (close approximate from home to workplace, comfortable schedule, adequate remuneration, freedom to work, job security, good relationship with staff) as well as promotion and recognition of their personal and professional achievements, which should be continuous, so that the work is always a challenge.

\section{Discussion}

With regards to the definition of job satisfaction based on the theory, we could say that job satisfaction of these doctors is neither static nor a status but it is a process. It is not done but it is acquired while physicians adapt to their workplace and that modifies during the course of their working lives, because their devotion to occupational health is not considered as a life project, since the beginning of their working lives.

Concerning the other mentioned satisfactors, there is an agreement with those reported by other researchers such as working conditions that generate job satisfaction. They appreciate the autonomy and flexibility even though these conditions involve greater responsibility and high levels of stress.

But the above-mentioned satisfaction criteria are different from what Galanou et al. (2011) describes. They say that salary is one of the main generators of job satisfaction in the lower hierarchical level workers. However, the physicians who participated valued the compensation they received for their work a lot, even when professionals cannot be regarded as a lower hierarchical level. All of these points to a discrepancy between hierarchical level and salary of the physician dedicated to occupational health, which may be the result of a not satisfied necessity, but this may also reflect the report by OECD (2013), in which wages in Mexico are well below the average of other developed countries.

Other studies also consider the relationship between the staff as a very important dimension for job satisfaction among employees (OCC, 2013; Galanou et al., 2011).

Finally, this investigation agrees with the perception of British nurses that have permission to medicate with increased stress but also increased job satisfaction (Cousins and O'Donnell, 2011).

As for full immersion that the doctors who work in Occupational Health area have, it differs from what was mentioned by Rico (2012) saying that job satisfaction increases with the harmonization between 
work life and family life, which does not happen with doctors who like to spend their free time working on Occupational Health.

\section{Conclusion}

The conclusion about the methodology, the Grounded Theory, with its thoroughness and methodological rigor, allowed to strengthen and systematize the research, facilitating interpretative analysis of the data and getting an integral view of the construction of the job satisfaction of physicians who participated on the investigation. Researchers would not have achieved it if they had worked with a different methodology.

In reference to job satisfaction of physicians working in Occupational Health, it was concluded that in general, their perception is positive. This was not the case at the beginning of their work lives, but it increased adapting to the workplace. The tasks they perform, their working conditions and social relationships contributed to it.

Physicians recognize the stress generated by exposure to psychosocial factors. It is a reflection of autonomy and recognition given to them for their work.

Doctors do not establish a separation between their personal life and their work life, so it is not possible to refer to balance, harmonization or conciliation between both of them. There is no satisfaction with the balance, but perception of stagnation.

\section{Acknowledgment}

There were not any financial support, neither technical assistance to report.

\section{Conflict of Interest}

There is no conflict of interest.

\section{Author's Contributions}

María del Carmen López-García: Investigation's conception and design, acquisition of data analysis and interpretation of data.

María de los Ángeles Aguilera-Velasco: Investigation's conception and design, interpretation of data and reviewing for significant intellectual content.

\section{Ethics}

This article is original and contains unpublished material. The corresponding author confirms that the other author have read and approved the manuscript and no ethical issues involved.

\section{References}

Cousins, R. and C. Donnell, 2011. Nurse prescribing in general practice: A qualitative study of job satisfaction and work-related stress. Family Pract., 29: 223-227. DOI: 10.1093/fampra/cmr077

Cuadra, A. and A. Veloso, 2007. Leadership, business climate and job satisfaction in organizations. Revista Universum, 22: 40-56.

DOI: $10.4067 / \mathrm{S} 0718-23762007000200004$

Galanou, E., G. Georgakopoulos, I. Sotiropoulos and V. Dimitris, 2011. The effect of reward system on job satisfaction in an organizational chart of four hierarchical levels: A qualitative study. Int. J. Human Sci., 8: 485-915.

GALLUP, 2013. State of the global workplace. Report 2013, GALLUP.

Navarro-Astor, E., H. Roche-Aparisi and J. Fuentes-del-Burgo, 2012. Do we know with whom we work? Qualitative study on work and job satisfaction of building officials. Proceedings of the 15th International Congress of Project Engineering, Jul. 11-13, Valencia, pp: 368-378.

OECD, 2013. Index for a better life. OECD.

OCC, 2012. National survey. OCC.

ILO, 1998. Encyclopedia of health and safety at work ILO-INSHT. International Labor Organization.

ILO, 1985. Convenio 160. International Labor Organization.

Patton, M.Q., 2001. Qualitative research and evaluation methods 3. Sage Publication Inc., E.U.A.

Reutter, L. and J. Ford, 1996. Perceptions of public health nursing: Views from the field. J. Adv. Nurs., 24: 7-15. DOI: 10.1046/j.1365-2648.1996.01681.x

Rico, P., 2012. Job satisfaction in employees in Spain. J. Quantitative Meth. Econom. Bus., 14: 137-158.

Strauss, A. and J. Corbin, 2002. Bases of qualitative research: Techniques and procedures to develop Grounded Theory. Editorial Universidad de Antioquia, Colombia.x 